\title{
Antimicrobial resistance of bacteria associated with raw milk contaminated with antibiotics residues in Khartoum State, Sudan*
}

\author{
Limya, M. Warsma ${ }^{a *}$, Nazik, E.M. Mustafa ${ }^{b}$, and Ibtisam, E.M. El Zubeir ${ }^{a *}$ \\ a Department of Dairy Production, Faculty of Animal Production, University of Khartoum, Khartoum, Sudan \\ ${ }^{b}$ Department Food Hygiene and Safety, Faculty of Public and Environmental Health, University of Khartoum, Sudan \\ ${ }^{*}$ Corresponding author: Ibtisam, E.M. El Zubeir (Ibtisamelzubeir17@gmail.com), Limya, M. Warsma \\ (areejwarsmaq3@gmail.com)
}

How to cite this article: Warsma et al. Antimicrobial resistance of bacteria associated with raw milk contaminated with antibiotics residues in Khartoum State, Sudan. Veterinary Medicine and Public Health Journal 1(1);2020:15-21.

DOI: https://doi.org/10.31559/vmph2020.1.1.4

Received Date: 28/10/2019 Accepted Date: 28/12/2019

\begin{abstract}
In this study 300 milk samples (200 cows, 50 camels and 50 goats) were collected randomly from farms, sale points and collection points in Khartoum State during winter and summer and investigated for antibiotics residues. Detection of antibiotic residues was performed using two methods: Trisensor antibiotic test and Modified One Plate Test. Also, isolation and identification of bacteria in antibiotic contaminated milk and their resistance to some antibacterial agents were performed. Eighty (40\%) of the collected cow milk samples were positive to antibiotics residues, while all camel and goat milk samples were negative. Ten (12.5\%) positive samples were found during winter and 23 (28.75\%) were detected during summer from collection points. The positive samples from sale points $(47,58.75 \%)$ were $15(18.75 \%)$ during winter and 32 (40\%) during summer. The isolated Staphylococcus aureus $(2 ; 0.49 \%)$ and $S$. auricularis $(4 ; 0.98 \%)$ were sensitive to ampicillin, cephalaxin, cloxacillin and resistant to cefotaxime (75\%). Bacillus cereus (18; 4.4\%) showed resistance to ampicillin, cephalaxin and cloxacillin (100\%). Bacillus coagulans (3;0.7\%) and B. pummilus (4; 0.9$)$ were resistant to ampicillin and cloxacillin (100\%). SimlarlyB. sphaericus $(4 ; 0.9 \%)$ was resistant to cloxacillin (100\%) and $B$. amyloliquefanciens $(3 ; 0.7 \%)$ was resistant to ampicillin and cloxacillin (100\%). Klebsiella spp. isolates showed resistant to cloxacillin (100\%), ampicillin (66.7\%) and cefotaxime (50\%). All isolates of Moraxilla spp showed resistance to ampicillin, cloxacillin, cefotaxime and cephalaxin. Escherichia and Enterobacter isolates showed (100\%) resistance to ampicillin, cloxacillin and cephalaxin. The present study concluded that the quality of milk obtained from cows was lower compared to that of goats and camels. Also, high antibiotic residues were found in the milk samples collected during summer. The study suggested that more efforts are needed to improve milk hygiene and quality.
\end{abstract}

Keywords: raw milk; antibiotic residues; bacterial resistant; seasons.

\footnotetext{
* The abstract of this paper was presented atf the 4th International Conference and Industrial Exhibition on Dairy Science Park IV. Selçuk Üniversitesi, Konya, Turkey, 1-5/11/2017. http://dairysciencepark.org.pk/dsp2017
} 


\section{Introduction}

Antibiotics, as well as other veterinary drugs, are available in Nigeria, making drugs easily accessible by livestock farmers by the nomadic herdsman without veterinary prescription (Olatoye and Ogundipe 2013). Tetracycline, $\beta$-lactams and aminoglycosides are among the frequently administered antibiotics in livestock production (Diarra and Malouin 2014). Penicillin residues in milk are considered a great public health problem because of consumption of such contaminated milk could result in severe and fatal anaphylactic (allergic) reactions in penicillinsensitized persons (Salkind et al. 2001). Antibiotic residues in foods are of public health concerns due to transfer of antibiotic-resistant bacteria to humans as well as toxic effects that include carcinogenicity, mutagenicity, nephropathy, hepatotoxicity, bone marrow toxicity and allergy (Nisha 2008). It also creates technical problems in the dairy industry by interfering with the fermentation process through the inhibition of starter cultures used in the production of cheese and yoghurt resulting in financial losses (Padol et al. 2015). Hence, milk and milk products containing antibiotics are considered unsafe and unfit for human consumption (Samanidou et al. 2007). Sulfonamides are among the oldest groups of antibiotics, which are widely used in the treatment of bacterial diseases in dairy cattle (Chung et al. 2009). Richene (2007) observed that for the treatment of sick cattle in Kosovo, beta-lactam and sulfonamide antibiotics are used most commonly by home-owner. Other types of antibiotics are used too, such as tetracycline and macrolides (Sulejmani et al. 2012).

Said Ahmed et al. (2008) detected the presence of antibiotic residues in $38.9 \%$ of the examined milk samples in Khartoum State with high occurrence in sales points (55.6\%) compared to those from farms (22.2 and \%). Similarly, El Zubeir and El Owni (2009) showed that $12.25 \%$ and $6.66 \%$ of the milk samples were contaminated with antibiotic and sulphanomide, respectively. Khaskheli et al. (2008) detected 36.5\% positive beta-lactam antibiotics residues in unpasteurized market milk using microbial screening test and HPLC methods. Addo et al. (2010) found 3.1\% of raw cow milk samples were contaminated with antibiotic residues in Ghana. Moreover, Addoma et al. (2015) found high contamination rates with tetracyclines (34\% and $31 \%$ ), sulfonamides (31\% and $29 \%)$, gentamicin $(25 \%$ and $32 \%)$ and streptomycin (19\% and $26 \%)$ in raw and heated milk samples respectively, collected from South Darfur, Sudan. However neomycin was not detected,

The use of antibiotics in livestock is considered as one of the reasons for increased occurrence of antibiotic resistant strains of bacteria in both animals and human beings (Callie et al. 2012). Sierra et al. (2009) and Carlos (2010) found that antibiotic abuse is one or perhaps the most important cause of the high prevalence of resistance among bacteria. This includes the use of wrong antibiotics, wrong doses, or the use of antibiotics for diseases that cannot be treated with antibiotics. For instance, several resistant species of bacteria particularly members of the Staphylococci,
Enterococci, Klebsiella pneumoniae, and Pseudomonas $s p p$, are now a common phenomenon in health care institutions (Francis et al. 2005). Yagoub et al. (2005) found that bacteria isolated from raw milk (Staphlycoccus aureus, Citrobacter spp, Shigilla spp, E. coli and Enterobactor spp) showed wide range of multiple resistance to the tested antimicrobial agents (pencillin, clindamycin, amoxicillin and ampcillin). However, chloramphenicol showed the best antimicrobial effect against the tested organisms followed by gentamicin, novobiocin and carpencillin. El Zubeir et al. (2006b) found that Staphphylococcus aureus resisted to tetracycline, penicillin and amoxicillin cluveneic acid, while most of E. coli strains showed resistance towards erythromycin, tetracycline streptomycine and sulfamethoxazole-trimethoprim and kanamycin. The coagulase-negative staphylococci were highly resistant to penicillin (37.4\%), as well as several other antibiotics (Asaminew and Eyassu 2010).

\section{Material and methods}

\section{Sources and collection of milk samples}

This investigation was based on collecting raw milk samples from different farms, collection centers and sale points in Khartoum State (200 milk samples from cows' milk, 50 milk samples from camels' milk and 50 milk samples from goats' milk). The samples were collected during summer and winter seasons in order to study the presence of antibiotic residues and to isolate and identify the dominant bacteria that associated with the milk containing antibiotic residues.

The samples were collected into clean sterile bottles and transported into an ice box $\left(4-5^{\circ} \mathrm{C}\right)$ to the laboratories of University of Khartoum for analysis. The examination of the milk samples was performed at the Department of Dairy Production, Faculty of Animal Production and the Department of Food Hygiene and Safety Faculty of Public and Environmental Health.

\section{Microbiological examination}

The identification was done on the isolates from milk containing antibiotic residues.

\section{Sterilization}

Glass wares such as Petri dishes, test tubes, pipettes, flasks and bottles were sterilized in a hot oven at $160^{\circ} \mathrm{C}$ for one hour. Distilled water, tips and culture media were sterilized by autoclaving for 15 minutes at $121^{\circ} \mathrm{C}$ (Barrow and Feltham 1993).

\section{Preparation of samples and media}

The samples were initially shaken and the serial dilutions were made by taking $1 \mathrm{ml}$ of milk samples into $9 \mathrm{ml}$ sterile ringer's solution using a sterile pipette. Serial dilution was prepared $\left(10^{-1}-10^{-8}\right)$ according to Harrigan and McCance (1976). Then $0.02 \mathrm{ml}$ from selected dilution was carefully transferred into Petri dishes using a sterile automatic pipette.

All media were obtained in dehydrated forms and prepared according to the manufactures' instructions. Plate count agar (KGaA64271) and MacConkey agar were used for the primary culturing of milk samples.

\section{Isolation of cultures}

Sub-culturing of the primary isolates from solids media to solids media was done by picking of part from a typical and well defined colony with a sterile wire loop and streaked over fresh plate. Each organism was 
subculture on its selective medium. From solids media to liquid media was done by picking part of a colony with the sterile wire loop and transferred into the liquid medium. From liquid to solids media was done by streaking a loopfull of the culture on the solids medium. Then the inoculums were spread quickly over the surface of the medium by using a sterile glass rod. The plates were then left to dry for 15 minutes before incubation (Harrigan and McCance 1976).

Incubation of cultures

All inoculated solids and liquid media were incubated aerobically at $37^{\circ} \mathrm{C}$ for $24-48$ hours. However, MR- VP medium was incubated at $37^{\circ} \mathrm{C}$ for 2 days and sugars, Koser citrate, OF, and urea medium were incubated at $37^{\circ} \mathrm{C}$ for 3 up to 7 days.

\section{Examination of cultures}

Cultures on solids media were examined with naked eyes for growth and colonial morphology, whereas liquid media were examined for growth by change in color and accumulation of gases in sugars media (Barrow and Feltham 1993).

\section{Purification of isolates}

The predominated microorganisms from morphologically different colony types were selected from plate count agar or MacConkey agar. These isolates were purified by sub-culturing of well isolated typical colony into nutrient agar plate (S.d Fine Chem. Ltd 74056). The sub-culturing was repeated until pure colony was obtained by examination of it visually and by Grams stain. The cultures were then kept in a refrigerator at $4^{\circ} \mathrm{C}$ until used.

\section{Identification of isolated bacteria}

The identification of pure bacteria isolated was based on the primary tests, secondary biochemical tests and sugars fermentation tests. The primary tests used include Gram reactions (Harrigan and McCance 1976), catalase test, oxidase test, oxidation fermentation test (OF), glucose test, motility test, ability to grow in air and test for ability for anaerobic growth (Barrow and Feltham 1993).

The secondary biochemical tests used for identification of Gram positive bacteria include Vogues Prokauer (VP), nitrate, methyl-D-glucose pyranoside, L-arginine and urease. The sugars used sugars fermentation tests were fructose, mannitol, sucrose, lactose, mannose, maltose, xylose, raffinose and malibinuse (Barrow and Feltham 1993 and Sanousi et al., 2015). Also coagulase test was used for differentiation of staphylococci (Barrow and Feltham 1993).

The secondary biochemical tests used for identification of Bacillus spp. include Vogues Prokauer (VP), citrate utilization, starch hydrolysis and growth at $10 \% \mathrm{NaCl}$ and sugars fermentation tests that include glucose, saliain and xylose. The secondary biochemical tests used for identification of Gram negative bacteria were methyl red (MR), Vogues Prokauer (VP), Indole, Urease, citrate utilization and hydrogen sulphide and lactose fermentation (Barrow and Feltham 1993).

\section{Antibacterial sensitivity test}

Sensitivity test was done by suspending $5 \mathrm{ml}$ quantities of sterile nutrient broth in $15 \mathrm{~mm}$ capped tubes. One drop of bacterial suspension was transferred using sterile Pasture pipette and put on diagnostic sensitivity test media (Mueller and Hinton agar media). The Petri dishes were moved in around motion to spread the suspension on the media surface. The antibiotics discs were placed firmly on the inoculated plates on the middle of the media surface. The plates were allowed to stand at room temperature for 3 hours to allow antibiotic diffusion. The plates were then incubated at $37^{\circ} \mathrm{C}$ overnight. The results of this test were recorded by measuring the diameter of inhibition zone around the disc of each antibiotic (Baker and Breach 1980). Zone of inhibition (clearings) around the disc papers were measured with ruler. The diameter of each zone including the disc diameter was recorded and compared with the size of control strains, which has values listed in a standard (Baner et al. 1966).

\section{Milk antibiotic residue detection methods Modified one plates test}

To detect the antibiotic residues in the collected samples of milk, sterile paper discs were impregnated with milk from each sample using sterile forceps. The latter were added to dishes of nutrient agar with and overnight broth culture of Bacillus subtilis. The plates were examined after incubation at $37^{\circ} \mathrm{C}$ for 24 hours. An inhibition zone around the paper discs were considered as positive result (Koenon et al. 1995). Vegetative cells of Bacillus subtilis were added to nutrient agar plates (S.d Fine Chem. Ltd 74056) after being grown in nutrient broth (Hi Media M 002). Then one ampoule of lyphphilized culture of Bacillus subtilis was opened and rehydrated with one ml of nutrient broth. The content was mixed with sterile loop and transferred into test tube of nutrient broth. Plates of nutrient agar were incubated using one drop of suspension from each culture and incubated at $37^{\circ} \mathrm{C}$ overnight and inoculated into Petri dishes of nutrient agar and left to dry on the bench.

\section{Tri sensor antibiotic test}

The beta-lactams, sulfamides and tetracycline are simultaneously detected in milk samples. Two hundred $\mu \mathrm{l}$ of milk were added to the reagent microwell and hey were incubated at $40^{\circ} \mathrm{C}$ for three minutes. Then one dipstick was dipped into the reagent microwell and the incubation was continued for 3 minutes at $40^{\circ} \mathrm{C}$. After that, the color intensity of test lines was read and compared with the control line.

\section{Results}

Thirty-three (41.25\%) of the detected positive samples were found in the collection points, 10 $(12.5 \%)$ of them were detected during winter season, and 23 (28.75\%) during summer season. Similarly, the milk samples collected from the sale points revealed 47 (58.75\%) positive samples; 15 (18.75\%) of the positive were found during winter and 32 (40\%) of them were detected during summer (Table 1). Whereas all of the milk samples collected from the 


\begin{tabular}{llccc}
\hline \multicolumn{5}{l}{ Table(1): Occurrence of antibiotics residues in dairy animals in Khartoum State using two detection } \\
methods. & \multicolumn{4}{l}{ Sotal (\%) } \\
\hline Species & Sources & Winter & Summer & Tot \\
\hline \multirow{3}{*}{ Cows } & Collection points & $10(12.5 \%)$ & $23(28.75 \%)$ & $47(58.75 \%)$ \\
& Sale points & $15(18.75 \%)$ & $32(40 \%)$ & 0 \\
& Farms & 0 & 0 & 0 \\
Goats & Collection points & 0 & 0 & 0 \\
& Sale points & 0 & 0 & 0 \\
\multirow{5}{*}{ Camels } & Farms & 0 & 0 & 0 \\
& Collection points & 0 & 0 & 0 \\
& Sale points & 0 & 0 & 0 \\
\hline
\end{tabular}

different dairy farms showed negative results for the antibiotics residues using the two detection methods.

\section{Bacterial isolates}

The isolated bacteria from raw cow milk samples contaminated with antibiotics (Table 2) were found as $2(0.49 \%)$ S. aurous, one sample detected from the sale points and one from the collection point during summer season, $4(0.98 \%)$ isolates of $S$. aurularis were found in the milk samples, three samples from the sale points and one sample from the collection points, two samples were detected during winter and summer season. Also, three $(0.73 \%)$ isolates of Kelbesilla spp. were found; two samples were detected from the collection points and one from the sale points, one sample was detected during winter and two of them during summer season. Six (1.4\%) isolates of Mroxella spp. were found; two of them were found in the milk samples collected from the sale points and four from the collection points, five isolates were detected during summer and one isolate was found during winter season. The two (0.5\%) isolated Enterobactor spp. from the sales points were detected during summer season. Similarly, six (1.4\%) isolates of Escherichia spp., four of them were detected from the sale points and two from the collection points, one isolate was found during winter and five during summer season. Twenty six (6.6\%) isolates of Bacillus licheniformis were isolated from the collected milk samples, 15 species from the sales points and 11 from the collection points, nine isolates during winter and 17 during summer season. Three $(0.7 \%)$ isolates of $B$. coagulns were also found, two of them were detected in the sale points and one from the collection points during summer season (Table 2). Four (0.9\%) isolate was identified as $B$. sphaericus, two of them were detected from each of the sales points and the collection points. They were found as one isolates detected during winter and the three during summer season. Three $(0.7 \%)$ isolates of B. amyloiquefaciewns were detected from the sales points, two of the isolates detected during winter and one during summer season. The present results also found 18 (4.4\%) isolates of $B$. cereus were detected, 11 and 7 isolates were found during summer and winter seasons, respectively. Moreover 10 of them were from the milk samples collected from the sale points and 8 from the collection points.

\begin{tabular}{lccccc}
\hline \multirow{2}{*}{$\begin{array}{l}\text { Table(2): Frequency of isolated bacteria from raw cow milk samples contaminated with antibiotic residues } \\
\text { in sale and collection points in Khartoum State. }\end{array}$} \\
\cline { 2 - 5 } Bacteria species & \multicolumn{3}{c}{ Source } & \multicolumn{3}{c}{ Season } & \\
\cline { 2 - 5 } & Sale points & Collection points & Winter & Sum & Total \\
\hline S. aureus & 1 & 1 & - & 2 & $2(0.49 \%)$ \\
S. auricularis & 3 & 1 & 2 & 2 & $4(0.98 \%)$ \\
Klebsiella spp. & 2 & 1 & 1 & 2 & $3(0.73 \%)$ \\
Moraxella spp. & 2 & 4 & 5 & 1 & $6(1.4 \%)$ \\
Enterobacter spp. & 2 & - & - & 2 & $2(0.5 \%)$ \\
Escherichia spp. & 4 & 2 & 1 & 5 & $6(1.4 \%)$ \\
B. licheniformis & 15 & 11 & 9 & 17 & $26(6.6 \%)$ \\
B. coagulns & 2 & 1 & - & 3 & $3(0.7 \%)$ \\
B. pumilus & 3 & 1 & - & 4 & $4(0.9 \%)$ \\
B. spherieus & 2 & 2 & 1 & 3 & $4(0.9 \%)$ \\
B. amyloiquefaciens & 3 & - & 2 & 1 & $3(0.7 \%)$ \\
B. cereus & 10 & 8 & 7 & 11 & $18(4.4 \%)$ \\
\hline
\end{tabular}

\section{Antibiotic sensitivity test}

The isolated $S$. aureus $(2 ; 0.49 \%)$ and $S$. auricularis (4; $0.98 \%$ ) were sensitive to ampcillin, cephalaxin, cloxacillin and resistance to cefotaxime. $B$. cereus $(18 ; 4.4 \%)$ showed resistance towards ampcillin, cephalaxin and cloxacillin (100\%), while sensitive to cefotaxim (27.7\%). Bacillus coagulans (3; $0.7 \%$ ) and Bacillus pummilus (4;0.9) were resistance to ampcillin and cloxacillin (100\%), however they were sensitive to cephalaxin (33.3\% and 50\%, respectively). Bacillus sphaericus (4; 0.9\%) was sensitive to ampcillin (25\%), cephalaxin (75\%) and cefotaxime (50\%) and resistance to cloxacillin (100\%). Bacillus amyloiquefamciens (3; 0.7\%) were resistance to ampcillin, cloxacillin and cefotxime (100\%). Bacillus lichearformis was resistance to ampcillin and cloxacillin (100\%) and sensitive to cefotaxime (67.93) and cephalaxin (75\%). Klebsilla isolates showed sensitivity to ampcillin (33.3\%), cephalaxin (100\%), cefotaxime (50\%) and resistance to cloxacillin (100\%). All isolated of Moraxilla spp showed resistance to ampcillin, cloxacillin, cefotaxime and cephalaxin. Escherichia and Enterobacter isolates showed 
resistance to ampcillin, cloxacillin and cephalaxin, as shown in Table 3 and 4.

\begin{tabular}{lcccc}
\hline $\begin{array}{l}\text { Table(3): The overall antimicrobial susceptibility test for the isolated bacteria from raw cow milk } \\
\text { contaminated with antibiotics residues }\end{array}$ & \multicolumn{3}{c}{ Antibiotic } \\
\cline { 2 - 5 } Organisms & Ampcillin & Cephalaxin & Cefotaxime & Cloxacillin \\
& + & + & + & - \\
\hline S. aureus & - & + & + & - \\
S. auricular & - & + & + & - \\
Bacillus cereuc & - & + & + & - \\
Bacillus coagulans & - & + & + & - \\
Bacillus pummilus & + & + & + & - \\
Bacillus sphaericus & - & + & + & - \\
Bacillus amyloique famciens & - & + & + & - \\
Bacillus lichearformis & + & - & - & - \\
Kelbsiella spp & - & - & + & - \\
Moraxella spp & - & - & + & - \\
Escherichia spp & - & & \\
Enterobacter spp & - & & + & - \\
\hline
\end{tabular}

\begin{tabular}{|c|c|c|c|c|c|c|c|c|c|c|c|c|}
\hline \multirow{3}{*}{ Organisms } & \multicolumn{12}{|c|}{ Antibiotic } \\
\hline & \multicolumn{3}{|c|}{ Ampcillin } & \multicolumn{3}{|c|}{ Cephalaxin } & \multicolumn{3}{|c|}{ Cefotaxime } & \multicolumn{3}{|c|}{ Cloxacillin } \\
\hline & $\mathrm{S}$ & I & $\mathrm{R}$ & $\mathrm{S}$ & I & $\mathrm{R}$ & $S$ & I & $\mathrm{R}$ & $\mathrm{S}$ & I & $\mathrm{R}$ \\
\hline S. aureus & 100 & 0 & 0 & 100 & 100 & 0 & 0 & 100 & 0 & 0 & 0 & 100 \\
\hline S. auricular & 0 & 0 & $\mathrm{I} 00$ & 75 & 25 & 0 & 50 & 50 & 0 & 0 & 0 & 100 \\
\hline Bacillus cereuc & 0 & 0 & 100 & 0 & 0 & 100 & 27.7 & 55.7 & 16.6 & 0 & 0 & 100 \\
\hline Bacillus coagulans & 0 & 0 & 100 & 33.3 & 66.7 & 0 & 0 & 100 & 0 & 0 & 0 & 100 \\
\hline Bacillus pummilus & 0 & 0 & 100 & 50 & 50 & 100 & 25 & 75 & 0 & 0 & 0 & 100 \\
\hline Bacillus sphaericus & 25 & 75 & 0 & 75 & 25 & 0 & 50 & 50 & 0 & 0 & 0 & 100 \\
\hline Bacillus amyloiqueamciens & 0 & 0 & 100 & 75 & 25 & 0 & 76.93 & 23.07 & 0 & 0 & 0 & 100 \\
\hline Bacillus lichearformis & 0 & 0 & 100 & 0 & 0 & 100 & 75 & 25 & 0 & 0 & 0 & 100 \\
\hline Kelbsiella spp & 33.3 & 66.7 & 0 & 100 & 0 & 0 & 0 & 100 & 0 & 0 & 0 & 100 \\
\hline Moraxella spp & 0 & 0 & 100 & 0 & 0 & 100 & 0 & 0 & 100 & 0 & 0 & 100 \\
\hline Escherichia spp & 0 & 0 & 100 & 0 & 0 & 100 & 0 & 100 & 0 & 0 & 0 & 100 \\
\hline Enterobacterspp & 0 & 0 & 100 & 0 & 00 & 100 & 0 & 100 & 0 & 0 & 0 & 100 \\
\hline
\end{tabular}

\section{Discussion}

The milk samples contaminated with antibiotics from sale points were higher than the samples collected from collection points (Table 1). This might be because milk sellers mix different milk from any sources and used to add antibiotics to milk to preserve and prolong its shelf life (Said Ahmed et al. 2008). The residues of antibiotics are harmful when transfer to human through milk resulting in therapy failure and development of antibiotics resistant organisms (Yagoub et al. 2005; El Zubeir et al. 2006; El Zubeir et al. 2012). The present result supported El Zubeir and El Owni (2009) who showed that $6.66 \%$ and $12.25 \%$ of the milk samples were contaminated with antibiotic and sulfonamide, respectively. Similarly, Addoma et al. (2016) reported that contamination with beta-lactams was higher in milk samples collected from the sale points $(37 \%)$ than in the samples from dairy farms $(32 \%)$, The values were higher than that reported by Movassagh and Karami (2010) who found 5\% of raw milk samples were positive for antibiotic residues. They indicated that the variation might be due to the differences of drug that used in the study areas and also variation in the drug withdrawal period of the antibiotics used. Values were on line with Sulejmani et al. (2012) who found that out of 127 samples of milk, al. 2006). Also, in many cases, cows wet conditions and was possibly contaminated with soil, in which B. cereus is abundant. B. cereus count was four times higher $(201 \mathrm{cfu} / \mathrm{mL})$ when cows had been housed compared to on pasture; $50 \mathrm{cfu} / \mathrm{mL}$
64 were contaminated with beta-lactam residues, and 24 with sulfonamide residues. Khaskheli et al. (2008) found that in Pakistan, $36.5 \%$ of the total of raw milk samples were contaminated with beta-lactam residues. Similarly, in Turkey, Kaya and Filazi (2010) confirmed the presence of beta-lactam residues in $44 \%$ out of the total of 1109 raw milk samples analyzed in Kenya, 21\% showed contamination with antibiotic residues. Also, in Germany, Kress et al. (2007) reported that $1.6 \%$ of the samples showed the presence of sulfonamide residues. However, a study conducted by Tolentino et al. (2005) in Mexico using the screening method, showed the number of samples detected with sulfonamide residues amounted to $51.3 \%$ of the total of analyzed samples. However, Chung et al. (2009) found the presence of sulfonamides was verified only in 4 samples out of 269 in the Republic of Korea.

The higher incidence of isolated bacteria was found to be $B$. lichearformis followed by B. cereus (Table 2). This might be due to the improper hygiene and sanitation condition, poor cleaning and marketing environment in addition to primitive system of transportation and marketing (Elmagli and El Zubeir 2006a). Feeding silage contaminated with $B$. cereus spores has been previously associated with the $B$. cereus spore count (Magnusson et were fed silage that was harvested in (0,Connell et al. 2013). The bacteria isolated (S. aureus, $S$. auricularis, Klebsiella, Moraxella, Enterobacter, Escherichia, B. coagulns, B. pumilus, B. spherieus) from from the milk in the present study showed wide range 
of multiple resistances to the tested antimicrobial agents. The results supported Megersa et al. (2012) who isolated Staphylococcus aureus (53.5\%); Streptococcus agalactiae (26.5\%), E. coli (12.5\%), Klebsiella spp (2.5\%) and Enterobacter spp (5\%) from mastitis positive quarters. Prevalence of Staphylococcus aureus indicated contagious mastitis was prevailing in studied farms, which is associated with unhygienic milking practice and poor herd health management (Megersa et al. 2012). E. coli 0157:H7 and Salmonella spp were isolated from $10.1 \%$ of raw milk samples in Tanzania (Dagmar et al. 2013). Also, Pant et al. (2013) reported that fifty samples, from all the samples were containing $E$. coli and Micrococcus, 40 samples were containing Lactobacillus, 35 samples were containing Salmonella and 30 samples were containing $S$. aureus, Klebsiella and other bacterial strains in India. $S$. aureus, Bacillus sphaericus and Kelbsiella were more sensitive to Ampcillin, Cephalaxin and Cefixime. Bacillus coagulans, Bacillus pummilus, Bacillus sphaericus and Bacillus lichearformis were sensitive to Cephalaxin and Cefixime. However, all the isolates were resistant to Cloxcillin. Bacillus species were resistant to Ampicillin except Bacillus sphaericus. Moraxella, Escherichia Enterobacter and Citrobacter were resistant to Ampicillin and Cephalaxin. This indicated these antibiotics are commonly used in milk by sellers and farmers. In antibiotic sensitivity test, the isolates of $S$. aureus were found to be resistant to penicillin, Pant et al. (2013) found that E. coli was resistant to tetracycline and Salmonella was resistant to penicillin, while Klebsiella were resistant to penicillin, chloramphenicol and erythromycin. These studies supported El Zubeir et al. (2006) and El Zubeir et al. (2012).

\section{Conclusion}

This study presented that there was a lack of hygiene measurement at milk production chain and this might be due to prevalence of some bacterial strain and occurrence of antibiotic residues, which might affect the keeping quality and safety of raw milk as well as the products derived from it. The high occurrence of antibiotics residues in milk samples collected from the sale points and collection points might be due to the adulteration by addition of antibiotic to the milk in order to prolong its shelf life. All of camels and goats milk samples studied were free from antibiotics residues. The study indicated that there was some resistance of the isolated bacteria in milk samples towards some selected antibiotics. Hence vaccination programs for epidemic diseases should be applied in order to minimize the need for antibiotics treatment; however, education program in the uses of antibiotics and its withdrawal periods should be implemented for farms owners and labors.

\section{Note}

Refaad and VMPHJ remain neutral with regard to jurisdictional claims in published institutional affiliation.

\section{References}

[1] Addo. KK., Mensah. GI., Aning. KG., Nartey. N., Nipah. GK., Bonsu. C., Akeh. ML. \& Smits. HL., Microbiological quality and antibiotic residues in informally market raw cow milk within the coastal Savannah zone of Ghana, Trop Med Int Health, 16(2)(2011),

227-232, https://doi.org/10.1111/j.1365-3156.2010.02666.x

[2] Addoma. FE., Abdelgadir. AEEl., Nahas. A. \& El Zubeir. I E M., Risk factors associated with antimicrobial residues in the milk consumed in Nylah, South Darfur State, Sudan, University of Khartoum Journal of Veterinary Medicine and Animal Production, 7(1)(2016)(2010), 22-32.

[3] Asaminew. T. \& Eyassu. S., Microbial of raw cow's milk collected from farmers and dairy cooperatives in Bahr Dar Zuria and Mecha District, Ethiopia, Agric. Biol. J. N. Am., 2(1)(2010),

29-33, https://doi.org/10.5251/abjna.2011.2.1.29.33

[4] Baker. FG. \& Breach. MR., Antibiotic Susceptibility Testing Medical Microbiology Techniques, Buffer Worth and Co. Publishers Ltd., (1980), pp. 343350.

[5] Baner. AW., Kirby. M. \& Sheris. JC., Antibiotic susceptibility testing by standard disk method, Am J Clin Path, 45(1966), 493-496.

[6] Barrow. GI. \& Felthan. RK., Cowan and Steel Manual for the Identification for Medical Bacteria, 3rd ed., Cambridge, (1993)

[7] Callie. HT., Amy. P., Robert. EJ., Partha. P R. \& Katharine. FK., Excretion of antibiotic resistance genes by dairy calves fed milk replacers with varying doses of antibiotics, Journal of Front Microbiology, 3(2012), 139-143, https://doi.org/10.3389/fmicb.2012.00139

[8] Carlos. F., Global perspectives of antibiotic resistance. Antimicrobial resistance in developing countries, US Springer Science and Business Media, (2010), pp 3-14.

[9] Chung. HH., Lee. JB., Chung. YH. \& Lee. KG., Analysis of sulfonamide and quinolone antibiotic: residues in Korean milk using microbial assays and high performance liquid chromatography, Food Chemistry, 113(1)(2009), 297-301, https://doi.org/10.1016/j.foodchem.2008.07.021

[10] Dagmar. 1., Schoder. M., Andreas. B., Lema. B. \& Laffa. J., Microbiological quality of milk in Tanzania: From Maasai stable to African consumer table, Journal of Food Protection, 76(11)(2013), https://doi.org/10.4315/0362-028x.jfp-13-101

[11] Diarra. MS. \& Malouin. F., Antibiotics in Canadian poultry productions and anticipated alternatives, Front. Microbial., 5(2014),282-291, https://doi.org/10.3389/fmicb.2014.00282

[12] El Sanousi. SM., Said. KB., Elbager. S., Awad. A., Rodwan. K. \& Eltom. KH., A flow chart for the identification of Staphylococcus species, Journal of Veterinary Medicine and Animal Production, 6(2)(2015), 93-97.

[13] El Zubeir. I E M., El Hassan. MEM. \& Yagoub. Sanaa. 0., Preservation of raw milk of Khartoum 
State (Sudan) by the lacto-peroxidase systems, International J. of Dairy Science, 1(2)(2006), 155160.

[14] El Zubeir. I E M. \& El Owni. O A0., Antimicrobial resistance of bacteria associated with raw milk contaminated by chemical preservatives, World Journal of Dairy and Food Sciences, 4(1)(2009), 65-69.

[15] El Zubeir. I E M., Kiessling. S., Kutzer. P., Wieler. LH. ,El Owni. O A O., Characterization of tetracycline-resistant Staphylococcus aureus isolated from bovine mastitis in Khartoum State, Sudan. University of Khartoum. Journal of Veterinary Medicine and Animal Production, 3(2)(2012), 53-64.

[16] Elmagli. 0 A O., El Zubeir \& Ibtisam. F M., Study on the hygienic quality, Journal of Animal and Veterinary Science, 1(1)(2006), 12-17.

[17] Francis. JS., Doherty. M C. \& Lopatin .U., Severe community-onset pneumonia in healthy adult caused by Methicillin resistant Staphylococcus aureus carrying Panton Valentine leukocidin gene; Clin. Infect. Dis.; 40(2005),100-107.

[18] Harrigan. W F. \& McCane. M E., Laboratory Methods in Food and Dairy Microbiology, Academic Press, London, (1976)

[19] Khaskheli. M., Malik. RS., Arain. MA., Soomro. A H. \& Arain. HH., Detection of $\beta$-lactam antibiotic residues in market milk, Pakistan Journal of Nutrition, 7(5)(2008), 682-685, https://doi.org/10.3923/pjn.2008.682.685

[20] Kress. C., Seidler. C., Kerp. B., Schneider. E. \& Usleber. E., Experience with an identification and quantification program for inhibitor-positive milk sample, Annal. Chim. Acta, 586(1-2)(2007), 275279, https://doi.org/10.1016/j.aca.2006.10.013

[21] Koenen. DK., Okerman. L., De Zutter. L., Degroodt. M., Van Hoof. J. \& Srebrnik. S., A one-plate microbiological screening test for antibiotic residue testing in kidney tissue and meat: An alternative to the EEC four-plate method, Food Additives and Contaminants, 12(1)(1995), 77-82, https://doi.org/10.1080/02652039509374281

[22] Marshall. RT., Standard Methods for the Examination of Dairy Products. The 16th ed. American Public Health Association (APHA), Washington DC, (1992)

[23] Megersa. B., Manedo. A., Abera. M., Regassa. A. \& Abunna. F., Mastitis in lactating cows at Hawassa town: Prevalence, risk factors, major bacterial causes and treatment response to routinely used antibiotics, American-Eurasian Journal of Scientific Research, 7(2) (2012) 86-91.

[24] Movassagh. M H. \& Karami. AR., Determination of antibiotic residues in bovine milk in Tabriz, Iran, Global Veterinarian Studies, 5(3)(2010), 195-197.

[25] Nisha A R., Antibiotics residues - A global health hazard, Vet. World, 2(2)(2008), 375-377, https://doi.org/10.5455/vetworld.2008.375-377

[26] O'Connell. A., Ruegg. PL. \& Gleeson. D, Farm management factors associated with the Bacillus cereus count in bulk tank milk. Irish Journal of Agricultural and Food Research, 52(2)(2013), 229-241.

[27] Olatoye. I O. \& Ogundipe. GAT., Quantitative analysis of ox-tetracycline residue in beef and chicken meat from cities of southwest Nigeria, Bull. Anim. Health Prod. Afr., 61(2013), 39-48.

[28] Padol. AR., Malapure. CD., Domple. VD. \& Kamdi. BP., Occurrence, public health implications and detection of antibacterial drug residues in cow milk. Environ, We. Int. J. Sci. Technol., 10(2015), 7-28.

[29] Pant. R., Nirwa. S. \& Rai. N., Prevalence of antibiotic resistant bacteria and analysis of microbial quality of raw milk samples collected from different regions of Dehradun, International Journal of Pharm. Tech. Research, 5(2)(2013), 804-810.

[30] Richene. RG., Investigation of safe level testing for beta-lactam, sulfonamide and tetracycline residues in bovine milk, Doctoral Thesis, Salne Regina University, USA, (2007)

[31] Said. Ahmed. AME., El Zubeir. IEM., El Owni. OAO. \& Ahmed. KAM., Assessment of microbial loads and antibiotics residues in milk supply in Khartoum State, Sudan, Research Journal of Dairy Sciences, 2(3)(2008) 57-63.

[32] Salkind. AR., Cuddy. PG., Foxworth. JW., Is this patient allergic to penicillin? An evidence-based analysis of the likelihood of penicillin allergy, $J$. Am. Med. Assoc., 285(2001), 2498-2505.

[33] Samanidou. VF., Nisyriou. SA. \& Papadoyannis. IN., Residue analysis of penicillins in food products of animal origin by HPLC: A review, J. Liq. Chromatogr. Relat. Technol., 30(9-10)(2007), 1145-1204,

https://doi.org/10.1080/10826070701274320

[34] Sierra. D., Sanchez. A., Conteras. A,. Corrales. C., Morales. C.T., de Lafe. C., Guirao. I. \& Gonzalo. C., Detection limits of four antimicrobial residue screening test for $\beta$-lactam in goat's milk, J. Dairy Sci., 92(8)(2009), 3585-3591, https://doi.org/10.3168/jds.2008-1981

[35] Sulejmani. Z., Shehi. A., Hajrulai. Z., Mata. E., Abuse of pharmaceutical drugs-antibiotics in dairy cattle in Kosovo and detection of their residues in milk, Journal of Ecosystem and Ecography. 2(4)(2012), 114-116, 7625.1000114

[36] Tolentino. RG., Penez. M N., Gonzalez. GD., Arain. MA., Leon. SV. \& Lopez. MG., Flores. GP., Determination of the presence of 10 antimicrobial residues in Mexican pasteurized milk. Interciencia, 30(2005), 291-294.

[37] Yagoub Sanaa. 0, Awadalla Nazik. E. \& El Zubeir. IEM., Incidence of some potential pathogenic in raw milk in Khartoum North (Sudan) and their susceptibility to antimicrobial agents, Journal of Animal and Veterinary Advances, 4(3)(2005), 356-359. 